\title{
Efeitos de um programa de criatividade para professoras em alunos do ensino fundamental
}

\author{
Effects of a creativity training program \\ for teachers on elementary \\ school students
}

Fernanda do Carmo Gonçalves dos SANTOS ${ }^{1}$

Denise de Souza FLEITH²

\begin{abstract}
Resumo
Este estudo, com delineamento quase-experimental, objetivou investigar os efeitos, a curto e médio prazo, de um programa de criatividade para professoras. Foram analisados a criatividade, o autoconceito, a motivação para aprender e a percepção de clima para criatividade em sala de aula de alunos do $3^{\circ}$ ano do ensino fundamental. Participaram 119 crianças, sendo 71 do grupo de tratamento e 48 do grupo controle, e 5 professoras, dentre as quais 3 foram treinadas. Foram utilizados o Teste Torrance de Pensamento Criativo e as Escalas de Avaliação da Motivação para Aprender de Alunos do Ensino Fundamental, Autoconceito Infanto-Juvenil e Percepção de Clima para Criatividade em Sala de Aula. Os resultados indicaram ganhos nos escores de criativdade e percepção do clima para a criatividade a curto e médio prazo, de autoconceito global e familiar a médio prazo, e de motivação intrínseca a curto prazo a alunos das professoras treinadas. Conclui-se que é viável e eficaz implementar programas de criatividade no contexto escolar.
\end{abstract}

Palavras-chave: Autoconceito; Criatividade; Docentes; Motivação; Treinamento.

\begin{abstract}
The purpose of this quasi-experimental study was to investigate short and medium-term effects of a creative program for teachers. Creative ability, self-concept, motivation to learn, and perception of the classroom climate for creativity were assessed in $3^{\text {rd }}$ grade students. The participants included 119 children, among which 71 composed the treatment group, 48 composed the controle group, and 5 were teachers (among whom, 3 were trained). The following instruments were used: the Torrance Test of Creative Thinking, the Scale for Evaluation of Motivation to Learn for Elementary

1 Universidade Federal do Recôncavo da Bahia, Centro de Formação de Professores. Av. Nestor de Melo Pita, 535, Centro, 45300-000, Amargosa, BA, Brasil. Correspondência para/Correspondence to: F.C.G. SANTOS. E-mail: <gs.fernandacarmo@gmail.com>.

2 Universidade de Brasília, Instituto de Psicologia, Departamento de Psicologia Escolar e do Desenvolvimento. Brasília, DF, Brasil. Artigo baseado na tese de F.C.G. SANTOS, intitulada "Intervenção em criatividade para professoras e mães: efeitos no rendimento escolar, autoconhecimentos, motivação e habilidades criativas de alunos do $3^{\circ}$ ano do ensino fundamental". Universidade de Brasília, 2015.
\end{abstract}


School Students, the Self-concept Scale for Children and Youth, and the Classroom Environment for Creativity Scale. The results indicated higher ratings of: creative ability and perception of classroom climate for creativity in the short and medium run, global and family self-concept in the medium run; and intrinsic motivation in the short run in the trained teachers' students. It was concluded that the implementation of creativity programs in the school context is viable and effective.

Keywords: Self-concept; Creativity; Faculty; Motivation; Training.

A criatividade tem sido cada vez mais reconhecida como recurso importante para a promoção do bem-estar mental do indivíduo e para o avanço econômico e social de um país. Desde que haja condições favoráveis e uso de estratégias adequadas, essa habilidade pode ser desenvolvida (Sawyer, 2012; Wechsler \& Souza, 2011). Embora não exista um consenso quanto à definição do termo criatividade, especialistas da área concordam que esse fenômeno implica a emergência de algo novo, aceito como útil pela sociedade (Alencar \& Fleith, 2009; Amabile, 1989; 1996; 2012; Csikszentmihalyi, 1996; Stein, 1974). No Modelo Componecial de Criatividade (Amabile, 1989; 1996; 2012), adotado como referência neste estudo, é explicitado que um produto ou resultado será considerado criativo se for novo, útil e a tarefa possibilitar múltiplas respostas. Nesse sentido, a autora destaca a necessidade de quatro componentes em interação para a emergência da expressão criativa: habilidades de domínio (bagagem de conhecimento), processos criativos (estilos de trabalho, estilos cognitivos, traços de personalidade e domínio de estratégias que favorecem a produção de novas ideias), motivação e contexto social.

Um dos contextos de incentivo à criatividade e fonte para a emergência de comportamentos criativos é a escola. O professor, de maneira especial, é um dos principais protagonistas na construção de um ambiente favorável à promoção da criatividade (Fleith \& Alencar, 2005; 2012; Lin, 2011). Contudo, estudos conduzidos no Brasil e em outros países indicam que essa habilidade ainda é pouco estimulada e compreendida por educadores, denotando que teoria e prática estão desarticuladas (Alencar \& Fleith, 2009; Aljughaiman \& Mowrer-Reynolds, 2005; Begheto, 2007; McCluskey, 2013; Nakano, 2009; Pfeiffer \& Wechsler, 2013; Rojanapanich \& Pimpa, 2011; Sawyer, 2012; Wechsler \& Souza, 2011).
Dessa forma, informação, formação inicial e continuada e apoio a profissionais da educação são imprescindíveis para que eles possam efetivamente implementar estratégias educacionais em sala de aula que estimulem o potencial criativo dos alunos. Diversos programas de treinamento de criatividade nesse sentido foram elaborados nos últimos 40 anos, muitos deles voltados para o contexto educacional (Alencar, Fleith, Shimabukuro, \& Nobre, 1987; Alfonso-Benlliure, Meléndez, \& García-Ballesteros, 2013; Bragotto, 1994; Fadel, 2010; Garaigordobil, 2006; Wechsler, 1987). Técnicas e materiais instrucionais foram desenvolvidos para facilitar a expressão da criatividade no ambiente escolar. Como consequência, vários estudos foram realizados com vistas a avaliar os efeitos de intervenções em criatividade (Ma, 2006; Nakano, 2011; Rose \& Lin, 1984; Scott, Leritz, \& Mumford, 2004). Os resultados revelam um impacto positivo, apoiando a premissa de que é possível ensinar a pessoa a pensar criativamente. Nakano (2011), por exemplo, investigou, por meio de revisão de literatura nacional e internacional, efeitos de programas de criatividade no contexto educacional e verificou que os grupos experimentais que participaram da intervenção apresentaram ganhos nas características criativas, além de maior motivação em sala de aula e aumento do rendimento acadêmico.

É fundamental, ao longo de um treinamento, desmistificar a ideia de que a criatividade é um dom inato e presente em poucos indivíduos, bem como mostrar ao professor seu importante papel no processo de desenvolvimento das habilidades criativas do aluno (Alencar \& Fleith, 2009; Sawyer, 2012). Esses autores ressaltam que fatores socioemocionais, como autoconceito e motivação, são relevantes e devem ser considerados no planejamento de um programa de criatividade. O autoconceito diz respeito à imagem subjetiva que o indivíduo 
possui de si mesmo e busca, ao longo da vida, manter ou melhorar (Alencar \& Fleith, 2009). Essa percepção é construída por meio de experiências pessoais e características de personalidade, diretamente afetadas pelo contexto em que a pessoa está inserida (Nelson, Rubin, \& Fox, 2005). Esse fenômeno é caracterizado como um sistema complexo, multidimensional e dinâmico de percepções, crenças e atitudes que o sujeito tem de si e, que por isso, pode variar em diferentes momentos e situações. A maneira como o indivíduo se percebe quanto às suas capacidades e envolvimento na realização de tarefas pode restringir ou favorecer o desenvolvimento do comportamento criativo. Entretanto, as variáveis afetivas são investigadas em menor grau do que as cognitivas (Fleith, 1999).

Resultados de pesquisas sobre efeitos de programas de criatividade têm indicado incremento dessa habilidade, mas no que diz respeito ao autoconceito os achados são divergentes (Flaherty, 1992; Fleith, 1999; Garaigordobil, 1999). É necessário investigar em maior profundidade a relação entre criatividade e autoconceito para melhor instrumentar professores no planejamento de estratégias educacionais de maneira a favorecer uma autoimagem positiva (Fleith, 1999; 2006). Em uma revisão de estudos de treinamento de criatividade, Amabile (1996) identificou que a maioria dos programas prioriza aspectos cognitivos em detrimento dos afetivos, especialmente a motivação. A motivação intrínseca diz respeito ao prazer e entusiasmo do indivíduo em realizar tarefas, ao passo que a extrínseca refere-se ao envolvimento com uma tarefa para alcançar uma meta externa (Ryan \& Deci, 2000). Resultado similar foi encontrado por Scott et al. (2004) ao constatarem, por meio de meta-análise, que a maior parte dos programas de criatividade privilegia o estímulo de características cognitivas. Diversos autores (Amabile, 1996; Fleith \& Alencar, 2010; Junge, 2006; Pinheiro-Cavalcanti, 2009; Santos \& Fleith, 2014; Sawyer, 2012) destacam que a força motivacional é fator fundamental para a ocorrência da criatividade e que a produção criativa não só requer envolvimento, mas também promove o desenvolvimento da motivação.

O objetivo deste estudo foi, portanto, examinar os efeitos, a curto e médio prazo, de um programa de criatividade para professoras nas habilidades criativas, no autoconceito, na motivação para aprender e na percepção do clima para criatividade em sala de aula de alunos do $3^{\circ}$ ano do Ensino Fundamental. Para tanto, foi utilizado um delineamento quase-experimental.

\section{Método}

\section{Participantes}

Cento e dezenove alunos de 5 turmas do $3^{\circ}$ ano do ensino fundamental de uma escola pública do estado de Minas Gerais e suas professoras participaram do estudo. Quarenta e oito alunos integraram o Grupo A (grupo controle) e 71 o Grupo B (grupo de tratamento - alunos cujas professoras participaram do programa de criatividade). As crianças do primeiro grupo tinham, em média, 7,72 anos (Desvio-Padrão - $D P=0,46) ; 18$ (37,3\%) eram do sexo feminino e $30(62,5 \%)$ do masculino. Com relação aos participantes do segundo grupo, 34 $(47,9 \%)$ eram meninas e 37 (52,1\%) meninos com idade média de 7,86 anos $(D P=0,39)$. Quanto à caracterização das professoras, quatro eram formadas em Pedagogia (sendo que uma delas também havia cursado Educação Física) e uma possuía o curso Normal Superior. A idade média das educadoras era de 33 anos, variando de 25 a 51 . O tempo médio de experiência no magistério oscilava entre 3 e 33 anos, sendo a média de 11,6 anos. Três docentes participaram da intervenção em criatividade e duas integraram o grupo controle.

\section{Instrumentos}

\section{Teste Torrance de Pensamento Criativo (Torrance, 1990)}

O objetivo desse teste é avaliar dimensões relacionadas ao processo criativo por meio da produção criativa expressa de forma verbal e figurativa. A validação desse instrumento para a população brasileira foi realizada por Wechsler (2004a; 2004b), 
contendo normas para estudantes do ensino médio e superior. Como os participantes deste estudo foram alunos do ensino fundamental, adotaram-se os procedimentos de correção recomendados por Alencar et al. (1987).

Foram utilizados quatro subtestes do Teste Torrance de Pensamento Criativo (TTCT, Torrance Test of Creative Thinking), sendo dois verbais e dois figurativos para cada uma das formas. Os dois subtestes figurativos são: Completando Figuras, no qual os respondentes devem juntar linhas às figuras incompletas, a fim de produzir desenhos diferentes e interessantes, e sugerir títulos aos mesmos (formas A e B); e Linhas (forma A) e Círculos (forma B), no qual os estudantes recebem o comando de desenhar utilizando os pares de linhas retas ou círculos apresentados.

Já os dois subtestes verbais são: (a) Aperfeiçoamento do Produto, no qual os participantes listam maneiras diferentes e interessantes de melhorar um elefante (forma A) e um macaco (forma B) de brinquedo de forma que eles possam se divertir mais; e (b) Usos Diferentes para uma caixa de papelão (forma A) e latas (forma B), nos quais é solicitado aos alunos sugestões de usos variados para o objeto. A forma A foi utilizada no pré-teste e no segundo pós-teste e a forma $B$ no primeiro pós-teste. Três características do pensamento criativo foram avaliadas por meio desses subtestes: (a) Fluência, número de respostas e soluções diferentes que os alunos fornecem a uma situação problema; (b) Flexibilidade, número de diferentes categorias de ideias ou formas diferentes de enfrentar uma situação problema; e (c) Originalidade, capacidade de produzir ideias raras ou incomuns estatisticamente infrequentes.

Baseado em Alencar et al. (1987), a Fluência foi avaliada com base no número de respostas válidas apresentadas pelos participantes em cada subteste. Para a Flexibilidade foram identificadas em quantas categorias se distribuíam as respostas dadas pelos alunos. Com relação à Originalidade, foi atribuído valor de zero, um ou dois pontos para cada resposta de acordo com a sua raridade estatística (acima de $4 \%$, entre 2 e $4 \%$ e abaixo de $2 \%$, respectivamente), considerando todas as respostas

\section{Escala de Autoconceito Infanto-Juvenil (Sisto \& Martinelli, 2004)}

O instrumento é utilizado para avaliar diferentes níveis de autoconceito de indivíduos na faixa etária de 8 a 16 anos. Os coeficientes de consistência interna de Cronbach variam entre 0,59 e 0,62, e para o escore total a precisão é de 0,78. A Escala de Autoconceito Infanto-Juvenil (EAC-IJ) possui cinco subescalas referentes à forma como as pessoas se percebem em contextos diferenciados. A primeira subescala, Autoconceito Pessoal, está relacionada aos sentimentos que o indivíduo tem sobre seu modo de ser e agir em diferentes situações. A segunda, Autoconceito Social, diz respeito às relações sociais com colegas e como o indivíduo se percebe nessas relações. A terceira, Autoconceito Escolar, refere-se à autoavaliação de suas possibilidades de liderança e de sucesso acadêmico. A quarta, Autoconceito Familiar, trata do comportamento adotado nas situações do dia a dia em casa com pais e irmãos. A soma dos quatro fatores fornece uma medida da quinta subsescala denominada Autoconceito Global. A escala é composta de 20 itens e para cada um deles o estudante tem três alternativas de respostas (nunca, às vezes e sempre).

\section{Escala de Avaliação da Motivação para Aprender de Alunos do Ensino Fundamental (Neves \& Boruchovitch, 2007)}

A escala foi construída e validada para alunos brasileiros do ensino fundamental ( $3^{\circ}$ ao $9^{\circ}$ ano). Tem por objetivo investigar a vontade dos alunos em estudar e aprender e suas alegações de motivos para se dedicarem, ou não, aos estudos. A Escala de Avaliação da Motivação para Aprender de Alunos do Ensino Fundamental (EMA) é composta por 31 itens e em cada um deles o aluno deve responder se a situação apresentada nas afirmações acontece sempre, às vezes ou nunca. Dois fatores são avaliados: Motivação Intrínseca (composto por 17 itens) e Motivação Extrínseca (composto por 14 itens). 0 total máximo de pontos que inclui a escala é 93 e, quanto maior a pontuação do aluno, maior sua 
orientação motivacional. Com relação à precisão, a escala possui um índice satisfatório de fidedignidade, com coeficiente alfa de Cronbach igual a 0,80, sendo de 0,86 para o Fator 1 (Ml) e 0,80 para o Fator 2 (ME).

\section{Escala sobre Clima para a Criatividade em Sala de Aula (Fleith \& Alencar, 2005)}

Esse instrumento, com 22 itens, visa identificar fatores associados à criatividade em sala de aula, segundo a percepção de alunos de $3^{\mathrm{a}}$ e $4^{\mathrm{a}}$ séries do ensino fundamental. Uma escala de frequência de 5 pontos é utilizada para responder aos itens - (1) nunca, (2) poucas vezes, (3) algumas vezes, (4) muitas vezes e (5) sempre -, devendo o aluno assinalar com um $X$ a opção que mostra melhor o que acontece em sua sala de aula. Os coeficientes de fidedignidade da escala variam de 0,55 a 0,73. Essa escala avalia cinco fatores: Suporte do Professor à Expressão de Ideias do Aluno (Fator 1), Autopercepção do Aluno em Relação à Criatividade (Fator 2), Interesse do Aluno pela Aprendizagem (Fator 3), Autonomia do Aluno (Fator 4) e Estímulo do Professor à Produção de Ideias do Aluno (Fator 5). Um estudo piloto foi realizado com uma criança da mesma faixa etária dos participantes deste estudo para investigar se ela era capaz de compreender os itens da escala. Não foi detectada necessidade de adequação do instrumento para sua aplicação nesta pesquisa.

\section{Procedimentos}

Após permissão da direção da escola para a realização da pesquisa, o estudo foi encaminhado e aprovado pelo Comitê de Ética em Pesquisa da Universidade de Brasília (Parecer n² 277.158/2013). Antes do início da intervenção, a primeira autora, que conduziu o treinamento, visitou duas vezes cada uma das cinco salas para verificar possíveis estratégias facilitadoras e inibidoras da expressão criativa dos alunos adotadas pelas docentes. Esses dados subsidiaram o planejamento dos dois primeiros encontros que foram elaborados a partir das demandas e realidade do contexto escolar.
No início do mês seguinte, foram aplicados os instrumentos em dois dias para cada turma no horário de aula para obtenção dos dados referentes ao pré-teste. Em seguida, procedeu-se à distribuição das professoras entre os dois grupos: duas professoras e seus estudantes foram alocados no Grupo A; três professoras e seus discentes, no Grupo B. A intervenção ocorreu em 11 encontros semanais com duração média de 1 hora e 30 minutos, em um intervalo de três meses, perfazendo um total de 16 horas e 30 minutos.

Nesse período, a primeira autora realizou três observações em cada turma das professoras participantes da intervenção para examinar se estava ocorrendo apropriação e utilização dos conteúdos trabalhados no treinamento na sala de aula. Essas observações duraram em média 1 hora e 30 minutos em cada turma e aconteceram após os $2^{\circ}, 5^{\circ}$ e $8^{\circ}$ encontros. Na primeira semana após a conclusão do programa, foi realizado o primeiro pós-teste em cada uma das cinco turmas.

Cerca de quatro meses depois, foi realizado o segundo pós-teste, envolvendo aplicação dos instrumentos em todas as turmas. Vale mencionar que uma vez por semana, após o término das aulas, era realizada, por parte da escola, reunião pedagógica com todas as professoras do período vespertino. Após essa reunião, as educadoras se agrupavam por ano escolar para elaborar o planejamento de aulas da semana. As três professoras participantes do treinamento deixaram de realizar a segunda parte da reunião para participarem da intervenção, enquanto as outras duas continuavam a fazer o planejamento como de costume.

\section{Programa de treinamento em criatividade para professoras}

O Modelo Componencial de Criatividade (Amabile, 1989; 1996) fundamentou a proposta de programa de treinamento da criatividade por privilegiar o papel da motivação, dos processos criativos e dos fatores contextuais no desenvolvimento da criatividade. O programa proposto visou contemplar fatores cognitivos, emocionais, motivacionais, sociais e pedagógicos promotores da habilidade 
criativa. Tratou-se de uma intervenção cujos encontros foram planejados com base nas observações realizadas em sala de aula e com informações e demandas trazidas pelas docentes ao longo das sessões. Em todos os encontros foi feita distribuição de um material de apoio relacionado com o tema abordado no dia. Outra estratégia adotada foi a entrega, ao final de cada sessão, de atividades para serem realizadas e registradas ao longo da semana e que eram debatidas nos primeiros 10 minutos da reunião seguinte. Essas atividades eram focalizadas na autoavaliação das professoras sobre suas condutas e observação do comportamento de seus alunos em sala de aula.

Outra atividade realizada em diversos encontros foi a adaptação dos planos de aula, no qual buscou-se ajustar o planejamento inicialmente elaborado pelas educadoras em consonância com estratégias discutidas na intervenção. Os seguintes temas foram discutidos nos encontros: conceitos, mitos, características e benefícios da criatividade, fatores promotores e inibidores da criatividade no ambiente escolar, clima de sala de aula para criatividade, motivação e autoconceito. Buscou-se apresentar os temas em cada um dos encontros de forma dinâmica, de modo a propiciar o diálogo e a exposição das percepções e experiências das professoras sobre o assunto debatido.

O treinamento ocorreu por meio de dinâmicas, exercícios (Virgolim, Fleith, \& Neves-Pereira, 2013) e discussões. Um exemplo de atividade foi entregar às professoras um checklist contendo fatores promotores e inibidores da criatividade. Exemplos de itens desse checklist eram: enfatizar os erros existentes e negligenciar os pontos positivos do aluno durante a correção da tarefa e relacionar a atividade com o contexto do aluno. Elas deveriam assinalar para cada dia da semana quais estratégias foram adotadas. Outro exemplo foi solicitar as professoras a elaboração de planos de ensino considerando as distintas estratégias discutidas na intervenção. A primeira autora, condutora do treinamento, participava apenas quando solicitado pelas participantes e no término do encontro, quando fornecia feedback do que foi observado no diálogo durante a elaboração dos planos de aula. O detalha- mento das sessões do programa de treinamento pode ser encontrado em Santos (2014).

\section{Resultados}

Os dados dos dois grupos de alunos foram examinados por meio das análises de variância univariada (Anova) para comparações intergrupos e teste $t$ pareado para comparações intragrupos. No pré-teste, ao comparar os grupos, os resultados apontaram diferenças significativas apenas para Flexibilidade Verbal e Motivação Extrínseca. Na primeira medida os alunos do Grupo B (grupo de tratamento) alcançaram médias mais elevadas e, na segunda, os do Grupo A (grupo controle).

No primeiro pós-teste (logo após o término da intervenção) a análise revelou diferenças estatisticamente significativas entre os grupos em relação à Fluência Verbal, Flexibilidade Verbal, Originalidade Figurativa e Motivação Extrínseca. Os alunos do Grupo B registraram médias superiores nas três primeiras variáveis e os do Grupo A na última variável. No segundo pós-teste (quatro meses após o término da intervenção) foi verificada diferença significativa nas medidas de Flexibilidade Verbal, Autoconceito Global e Fator 1, relativo à percepção do clima para criatividade em sala de aula (Suporte da Professora à Expressão de Ideias do Aluno). Os alunos do Grupo B registraram médias superiores as dos alunos do Grupo A nas três medidas (Tabela 1).

Também foi realizada análise intragrupo para examinar se houve diferença entre as três fases da coleta de dados para cada grupo de alunos. Em relação ao Grupo A, na comparação entre o pré-teste e o primeiro pós-teste, foi constatada diferença significativa apenas para Originalidade Figurativa, $t(40)=2,53, p=0,015$. Os alunos desse grupo registraram desempenho superior no pré-teste comparativamente ao primeiro pós-teste. Na comparação entre o pré-teste e o segundo pós-teste, a análise indicou diferenças significativas quanto à Fluência Figurativa, $t(39)=4,04, p<0,001$, Flexibilidade Figurativa, $t(39)=3,07, p=0,004$, Motivação Extrínseca, $t(37)=3,74, p=0,001$, Autoconceito Escolar, $t(39)=3,51, p=0,001$, Autoconceito 
Tabela 1

Média (M), Desvio-Padrão e valor de F e p dos Grupos A (Controle) e B (Tratamento) em características de Criatividade, Motivação para Aprender, Autoconceito e Clima de Sala de Aula para Criatividade considerando o Pré-teste, $1^{\circ}$ e $2^{\circ}$ Pós-teste

\begin{tabular}{|c|c|c|c|c|c|c|c|c|c|c|c|c|}
\hline \multirow{2}{*}{ Características } & \multicolumn{4}{|c|}{ Pré-teste } & \multicolumn{4}{|c|}{$1^{\circ}$ Pós-teste } & \multicolumn{4}{|c|}{$2^{\circ}$ Pós-teste } \\
\hline & $M$ & $D P$ & $F$ & $p$ & $M$ & $D P$ & $F$ & $p$ & $M$ & $D P$ & $F$ & $p$ \\
\hline \multicolumn{13}{|l|}{ Fluência Verbal } \\
\hline Grupo A & 10,47 & 6,94 & 3,10 & 0,09 & 11,27 & 7,14 & 5,43 & 0,02 & 13,36 & 9,09 & 2,47 & 0,12 \\
\hline Grupo B & 12,74 & 6,53 & & & 15,03 & 8,91 & & & 16,25 & 9,57 & & \\
\hline \multicolumn{13}{|c|}{ Flexibilidade Verbal } \\
\hline Grupo A & 6,92 & 3,80 & 5,50 & 0,02 & 6,33 & 3,74 & 8,63 & 0,004 & 7,68 & 4,41 & 4,93 & 0,03 \\
\hline Grupo B & 8,33 & 3,31 & & & 8,47 & 3,64 & & & 9,65 & 4,58 & & \\
\hline \multicolumn{13}{|c|}{ Originalidade Figurativa } \\
\hline Grupo A & 10,21 & 4,88 & 0,03 & 0,87 & 8,44 & 10,63 & 3,92 & 0,05 & 10,98 & 4,76 & 1,33 & 0,25 \\
\hline Grupo B & 10,38 & 5,67 & & & 10,63 & & & & 12,24 & 6,05 & & \\
\hline \multicolumn{13}{|c|}{ Motivação Extrínseca } \\
\hline Grupo A & 29,68 & 6,77 & 4,24 & 0,04 & 28,89 & 6,66 & 5,85 & 0,02 & 26,47 & 7,69 & 3,56 & 0,06 \\
\hline Grupo B & 26,94 & 6,68 & & & 26,50 & 7,48 & & & 23,78 & 6,68 & & \\
\hline \multicolumn{13}{|c|}{ Autoconceito Global } \\
\hline Grupo A & 28,78 & 6,64 & 1,88 & 1,74 & 27,35 & 5,01 & 0,47 & 0,50 & 26,24 & 4,80 & 4,55 & 0,04 \\
\hline Grupo B & 27,70 & 6,78 & & & 28,00 & 4,76 & & & 28,30 & 5,03 & & \\
\hline \multicolumn{13}{|l|}{ Fator 1} \\
\hline Grupo A & 3,93 & 0,88 & 2,53 & 0,12 & 3,83 & 0,84 & 2,65 & 0,11 & 3,67 & 0,93 & 8,64 & 0,004 \\
\hline Grupo B & 3,64 & 0,90 & & & 4,08 & 0,72 & & & 4,18 & 0,86 & & \\
\hline
\end{tabular}

Social, $t(39)=7,04, p<0,001$, Autoconceito Familiar, $t(38)=4,63, p<0,001$, e Autoconceito Global, $t(38)=3,51, p=0,001$.

Esses mesmos alunos alcançaram desempenho superior no pré-teste considerando as medidas de Motivação Extrínseca, Autoconceito Escolar, Autoconceito Social e Autoconceito Global. Já nas duas características da criatividade e no Autoconceito Familiar o resultado foi melhor no segundo pós-teste. O teste $t$ apontou diferenças significativas entre o primeiro pós-teste e o segundo pós-teste no que diz respeito à Fluência Figurativa, $t(41)=6,00, p<0,001$, Flexibilidade Figurativa, $t(41)=4,36, p<0,001$, Originalidade Figurativa, $t(41)=3,04, p=0,004$, Autoconceito Escolar, $t(2)$ $=2,32, p=0,025$, Autoconceito Social, $t(42)=6,36$, $p<0,001$, Autoconceito Familiar, $t(41)=4,99$, $p<0,001$, Motivação Intrínseca, $t(39)=2,14$, $p=0,039$ e no Fator 3 (Interesse do Aluno pela Aprendizagem), $t(19)=3,05, p=0,007$. No Autoconceito Escolar, Autoconceito Social, Motivação Intrínseca e Fator 3 as médias foram mais altas no primeiro pós-teste, ao passo que, no Autoconceito
Familiar e nas três características da criatividade, os alunos do Grupo A apresentaram escores mais elevados no segundo pós-teste.

Já na análise intragrupo do Grupo B, os resultados evidenciaram diferenças significativas entre o pré-teste e o primeiro pós-teste nas medidas de Fluência Verbal, $t(57)=2,20, p=0,032$, Flexibilidade Figurativa, $t(57)=2,86, p=0,006$, Motivação Intrínseca, $t(60)=2,26, p=0,028$, Motivação Extrínseca, $t(61)=3,56, p=0,001$, Fator $1, t(62)=3,69$, $p<0,001$, Fator $2, t(62)=2,71, p=0,009$, Fator 3, $t(62)=2,23, p=0,030$, Fator $4, t(62)=2,96, p=0,007$, e Fator $5, t(62)=2,87, p=0,013$. Na Motivação Extrínseca, as médias foram superiores no pré-teste. Já nas características da criatividade, nos fatores da percepção do clima para criatividade em sala de aula e Motivação Intrínseca os alunos desse grupo tiveram desempenho superior no primeiro pós-teste.

Compararam-se, também, os dados do pré-teste com os do segundo pós-teste. Foram observadas diferenças significativas em relação à Fluência Verbal, $t(58)=3,13, p=0,003$, Flexibilidade Verbal, $t(58)=2,28, p=0,026$, Fluência Figurativa, $t(58)=5,33$, 
$p<0,001$, Flexibilidade Figurativa, $t(58)=6,20$, $p<0,001$, Originalidade Figurativa, $t(58)=2,35$, $p=0,022$, Autoconceito Social, $t(54)=5,24$, $p<0,001$, Autoconceito Familiar, $t(54)=7,23$, $p<0,001$, Motivação Extrínseca, $t(57)=4,44$, $p<0,001$, Fator $1, t(59)=3,77, p<0,001$, Fator 2 , $t(59)=2,90, p=0,005$, Fator $3, t(58)=2,34, p=0,023$, Fator $4, t(59)=2,79, p=0,007$, e Fator 5, $t(59)=2,55, p=0,013$. No fator Autoconceito Social e Motivação Extrínseca, a pontuação foi mais alta no pré-teste. Já nas medidas de criatividade, dos cinco fatores da percepção do clima para criatividade em sala de aula e Autoconceito Familiar, o desempenho foi melhor no segundo pós-teste.

Os resultados sinalizaram ainda diferenças entre o primeiro pós-teste e o segundo pós-teste para Flexibilidade Verbal, $t(52)=2,44, p=0,018$, Fluência Figurativa $t(52)=4,26, p=0,006$, Flexibilidade Figurativa, $t(52)=2,83, p=0,007$, Autoconceito Social, $t(56)=7,62, p<0,001$, Autoconceito Familiar, $t(56)=7,23, p<0,001$, Motivação Intrínseca, $t(55)=2,05, p=0,045$, e Motivação Extrínseca, $t(56)=3,09, p=0,003$. Os alunos do Grupo B registraram desempenho superior no primeiro pós-teste em Autoconceito Social e nos dois tipos de motivação. Já as médias das medidas de criatividade e Autoconceito Familiar foram mais altas no segundo pós-teste quando comparado ao primeiro.

\section{Discussão}

Os resultados indicam que a intervenção trouxe efeitos positivos no desenvolvimento do potencial criador dos alunos, especialmente a curto prazo, em três medidas de criatividade. Contudo, vale ressaltar que em uma delas, Flexibilidade Verbal, os alunos do grupo de tratamento já apresentavam, no pré-teste, escores mais elevados do que os do grupo controle, fazendo com que se questionasse em que extensão os valores mais altos para esta característica no $1^{\circ}$ pós-teste do Grupo B eram consequência do treinamento. Além disso, na análise intragrupo, o grupo controle foi o único que não apresentou ganhos na comparação entre o pré- do grupo de tratamento apresentaram aumentos nos níveis da Fluência Verbal e Flexibilidade Figurativa. Em relação à primeira, considera-se que duas estratégias utilizadas durante o treinamento foram importantes para esse resultado: solicitar às docentes que elaborassem atividades ou adaptassem as perguntas dos livros no intuito de estimular a eliciação de várias respostas; e incentivá-las a permitir que todos os estudantes expressassem suas ideias oralmente, sem medo de serem ridicularizados com o feedback da educadora. Autoras, como Alencar e Fleith (2009) e Amabile (1989; 1996), apontam a implementação de atividades que levam o aluno a produzir diversas ideias como prática importante para a expressão criativa, bem como propor um clima seguro em aula para manifestá-las. Amabile (1996) também destaca o feedback detalhado, que valoriza o empenho e as conquistas da criança, como ação promotora da habilidade criativa.

Notou-se que ambos os grupos tiveram aumentos nas medidas de criatividade quando comparados seus desempenhos do pré-teste com o $2^{\circ}$ pós-teste. No caso do grupo controle, os ganhos foram relativos às três medidas de Criatividade Figurativa, enquanto que, no grupo de tratamento, os escores elevados foram observados em duas medidas de Criatividade Figurativa e em três da Verbal. No que diz respeito aos ganhos em Flexibilidade Figurativa e Originalidade Figurativa do Grupo B, um dos fatores que pode ter contribuído significativamente para o aumento dos níveis nessas duas medidas diz respeito às atividades implementadas nas aulas de artes. Durante o planejamento das professoras para a realização de uma tarefa nessa disciplina, em um dos primeiros encontros do programa, foi verificado que os discentes tinham pouca autonomia e opção de escolha no processo de elaboração dos produtos. A pesquisadora responsável pela condução do treinamento chamou atenção para a necessidade de dar, aos estudantes, maior liberdade nas suas criações e o direito de personalizá-las.

Esses dados justificam a defesa de Amabile (1996) da necessidade do uso da fantasia, do estímulo da autonomia e do senso de autocontrole em sala de aula para a promoção do potencial criador. 
Um dos possíveis motivos para não ter sido verificado um resultado tão expressivo a médio prazo é que, no segundo semestre do ano letivo, quando o treinamento já havia sido concluído, as cinco docentes tornaram a se reunir semanalmente durante as reuniões pedagógicas para elaborarem o plano de aula. Nesse sentido, formula-se a hipótese de que os estudantes do Grupo A tenham sido beneficiados no estímulo de seu potencial criador quando suas professoras se juntaram às colegas treinadas. Contudo, há que se considerar a possibilidade dos efeitos do treinamento serem menores a médio e longo prazo comparativamente a curto prazo.

A maioria dos programas tem seu impacto avaliado apenas logo após o seu término, impedindo que seja realizado um diagnóstico de suas reais contribuições na vida dos indivíduos participantes (Fleith, 2011; Mendonça, 2012; Nakano, 2011). Também é possível que a repetição dos instrumentos nas três fases de coleta de dados tenha influenciado nos resultados, já que pode ter ocorrido efeito de teste-reteste. Nesse sentido, conclui-se que o programa de treinamento contribuiu moderadamente para o desenvolvimento da criatividade dos alunos.

Com base nos achados, observa-se que, a curto prazo, o programa de criatividade pouco contribuiu para o desenvolvimento do autoconceito dos estudantes que tiveram suas docentes treinadas, pois não houve nenhuma mudança no primeiro pós-teste. Quatro meses após o término da intervenção, entretanto, constata-se um impacto positivo sobre o Autoconceito Global, já que os discentes do Grupo B, comparativamente aos do Grupo A, apresentaram desempenho superior nessa medida. Chama atenção o fato de só serem visualizadas mudanças no autoconceito quatro meses após o término da intervenção.

Peixoto (2003), por meio de análise de várias pesquisas, concluiu haver uma relativa estabilidade no autoconceito. Isso está atrelado à facilidade ou dificuldade de alterar a percepção que o indivíduo tem de si e está relacionada ao grau de cristalização de suas próprias opiniões. O mesmo autor, a partir de revisão da literatura, verificou que os níveis do autoconceito têm maior estabilidade no intervalo de 6 meses a 2 anos. Chapman e Tunmer (1997) detectaram que certas dimensões do autoconceito, como a percepção de competência e dificuldade em leitura, tem estabilidade de até cinco anos. Levando em conta esses aspectos, infere-se que uma intervenção com vistas a contribuir para o desenvolvimento de um autoconceito positivo deve ser feita ao longo da trajetória escolar do estudante.

Os resultados deste estudo sugerem que estimular criatividade não significa necessariamente promover um autoconceito positivo. Cabe considerar que a relação entre criatividade e autoconceito tem se mostrado muito tênue, conforme evidenciado em alguns estudos (Fleith, 1999; Stadler \& Kotze, 2006).

No que diz respeito à motivação para aprender, a comparação intragrupo sinaliza que o programa contribuiu positivamente para a orientação motivacional das crianças do Grupo B logo após o término da intervenção, já que foi o único a apresentar acréscimo significativo na Motivação Intrínseca e decréscimo na Motivação Extrínseca. Quatro meses após o término da intervenção, na comparação entre o pré-teste e segundo pós-teste, foi constatada redução nos níveis da Motivação Extrínseca nos dois grupos. Nesse sentido, conclui-se que o programa contribuiu moderadamente para o desenvolvimento da motivação para aprender, a curto prazo. Constata-se ainda, que o Grupo B destacou-se com resultados positivos na criatividade e na motivação intrínseca, reforçando a ideia de que esses dois fenômenos estão interrelacionados.

Cabe resaltar que, de acordo com Putwain, Kearsley e Symes (2012), essa relação não se dá de forma direta, havendo outros fatores importantes para a sua ocorrência. Esses autores verificaram que os estudantes que possuem percepção positiva sobre sua habilidade criativa também são mais motivados intrinsecamente. Foi diagnosticado, por meio dos resultados do Fator 2 (Autopercepção do Aluno com Relação à Criatividade) da Escala sobre Clima para a Criatividade em Sala de Aula, que somente os discentes do Grupo B desenvolveram uma percepção mais favorável nesse fator após seus professores participarem do programa. Outra variável importante para o aumento das forças motivacionais, de acordo com Ryan e Deci (2000) e Guima- 
rães (2004), seria a autonomia. Os estudantes do Grupo B, novamente, foram os únicos a apresentarem mudanças na percepção da autonomia na escala citada anteriormente.

Quanto à Percepção do Clima para Criatividade em Sala de Aula, o Grupo B obteve escore superior nos cinco fatores, tanto no primeiro quanto no segundo pós-teste em relação ao pré-teste. Os estudantes das educadoras treinadas foram os únicos a desenvolverem uma percepção mais positiva em todos os cinco fatores a curto e médio prazo e, nesse sentido, compreende-se que o programa colaborou positivamente no estabelecimento de um clima propício para a expressão da habilidade criativa em suas turmas. No $11^{\circ}$ encontro da intervenção, as professoras ressaltaram que a maior contribuição do treinamento foi propiciar uma mudança na relação com seus alunos, o que pode explicar em parte o resultado positivo acerca do clima para criatividade em sala de aula.

Considera-se que as seguintes ações realizadas durante a intervenção tenham contribuído para essa mudança: (a) destaque no encorajamento que se deu às professoras para fornecerem feedback detalhado ao aluno quanto às suas realizações, destacando pontos positivos, e (b) discussão nos encontros sobre como a relação professor-aluno pode influenciar no desenvolvimento da criatividade em sala de aula.

Esta pesquisa corrobora resultados de investigações anteriores cujas evidências apontam para os efeitos positivos de programas de criatividade (Ma, 2006; Nakano, 2011; Rose \& Lin, 1984; Scott, Leritz, \& Mumford, 2004), especialmente no que diz respeito à promoção de habilidades criativas. Entre as limitações do estudo, salientam-se a seleção da amostra de conveniência e o uso de dois instrumentos (Teste Torrance do Pensamento Criativo e Escala sobre Clima para a Criatividade em Sala de Aula) que não foram validados para a faixa etária ou ano escolar dos discentes participantes da pesquisa. A escala de autoconceito, por sua vez, foi validada com base apenas nos dados de estudantes de uma determinada região do estado de São Paulo.
Não foi foco de análise o tempo de magistério das professoras participantes, embora a literatura tenha indicado que essa variável pode influenciar no estímulo da criatividadde em aula (Castro \& Fleith, 2008). Em caso de replicação do treinamento, recomenda-se: (a) inserção do programa de criatividade como projeto de ação contínua da escola e sua inclusão à carga horária do professor; e (b) acompanhamento das educadoras, após o término dos encontros da intervenção, por meio de observação em sala de aula e posterior feedback individualizado, bem como de visitas quinzenais às reuniões dos professores para atender possíveis dúvidas e demandas trazidas pelas participantes no que diz respeito ao estímulo, em sala de aula, das habilidades criativas, motivação e autoconceito para aprender. Entre possibilidades de pesquisas futuras, encontram-se: (a) replicar este estudo com uma amostra maior; (b) conduzir um estudo longitudinal sobre os efeitos de programas de criatividade; (c) implementar uma intervenção em criatividade que focalize uma área específica do conhecimento; e (d) incluir a mensuração de outras características de criatividade, notadamente as consideradas emocionais, como fantasia, expressão de emoção etc., conforme recomendado por Torrance (1990) e Wechsler (2004a; 2004b), visto que apenas as cognitivas foram analisadas no presente estudo.

\section{Referências}

Alencar, E. M. L. S., \& Fleith, D. S. (2009). Criatividade: múltiplas perspectivas. Brasília: EDUnB.

Alencar, E. M. L. S., Fleith, D. S., Shimabukuro, L. A., \& Nobre, M. A. (1987). Efeitos de um programa de treinamento de criatividade para professores do ensino do primeiro grau nas habilidades de pensamento criativo do aluno. Interamerican Journal of Psychology, 21(1), 56-71.

Alfonso-Benlliure, V., Meléndez, J. C., \& García-Ballesteros, M. (2013). Evaluation of a creativity intervention program for preschoolers. Thinking Skills and Creativity, 10(1), 112-120. http://dx.doi.org/10.10 16/j.tsc.201 3.07 .005

Aljughaiman, A., \& Mowrer-Reynolds, E. (2005). Teacher's conceptions of creativity and creative students. Journal of Creative Behavior, 39(1), 17-34. http://dx.doi.org/ 10.1002/j.2162-6057.2005.tb01247.x 
Amabile, T. M. (1989).Growing up creative: Nurturing a lifetime of creativity. Buffalo, NY: The Creative Education Foundation Press.

Amabile, T. M. (1996). Creativity in context. Boulder, CO: Westview Press.

Amabile, T. M. (2012). Componential theory of creativity. Retrieved September 30, 2014, from http://www.hbs. edu/faculty/Publication\%20Files/12-096.pdf

Begheto, R. A. (2007). Does creativity have a place in classroom discussions? Prospective teacher's response preferences. Thinking Skills and Creativity, 2(1), 1-9. http://dx.doi.org/10.1016/j.tsc.2006.09.002

Bragotto, D. (1994). Programa experimental para o desenvolvimento da expressão poética em adolescentes (Dissertação de mestrado não-publicada). Pontifícia Universidade Católica de Campinas.

Castro, J. S. R., \& Fleith, D. S. (2008). Criatividade escolar: relação entre tempo de experiência docente e tipo de escola. Psicologia Escolar e Educacional, 12(1), 101-118.

Chapman, J. W., \& Tunmer, W. E. (1997). A longitudinal study of beginning reading achievement and reading self-concept. Bristish Journal of Educational Psychology, 67(3), 279-291. http://dx.doi.org/10.11 11/j.2044-8279.1997.tb01244.x

Csikszentmihalyi, M. (1996). Creativity: Flow and the psychology of discovery and invention. New York: Harper Collins.

Fadel, S. J. (2010). Avaliação de um programa de criatividade para professores no ensino superior (Tese de doutorado não-publicada). Pontifícia Universidade Católica de Campinas.

Flaherty, M. A. (1992). The effects of a holistic creativity program on the self-concept and creativity of third graders. Journal of Creative Behavior, 26(3), 165-171. http://dx.doi.org/10.1002/j.2162-6057.1992.tb0 1173.x

Fleith, D. S. (1999). Effects of a creativity training program on creative abilities and self-concept in monolingual and bilingual elementary classrooms (Unpublished doctoral dissertation). University of Connecticut, Storrs, United States.

Fleith, D. S. (2006). Desenvolvimento da criatividade no contexto escolar: integrando características personológicas e fatores ambientais. In M. C. R. A. Joly \& C. Vectore (Eds.), Questões de pesquisa e práticas em Psicologia escolar (pp.125-144). São Paulo: Casa do Psicólogo.

Fleith, D. S. (2011). Desenvolvimento da criatividade na educação fundamental: teoria, pesquisa e prática. In S. M. Wechsler \& V. L. T. Souza (Eds.), Criatividade e aprendizagem: caminhos e descobertas em perspectiva internacional (pp.33-51). São Paulo: Loyola.

Fleith, D. S., \& Alencar, E. M. L. S. (2005). Escala sobre o clima para criatividade em sala de aula. Psicologia: Teoria e Pesquisa, 21(1), 85-91. http://dx.doi.org/10.1 590/S0102-37722005000100012
Fleith, D. S., \& Alencar, E. M. L. S (2010). A inter-relação entre criatividade e motivação. In E. Boruchovitch, J. A. Bzuneck, \& S. E. R. Guimarães (Eds.), Motivação para aprender: temas atuais e aplicações no contexto educativo (pp.209-230). Petrópolis: Vozes.

Fleith, D. S., \& Alencar, E. M. L. S. (2012). Autoconceito e clima criativo em sala de aula na percepção de alunos do ensino fundamental. Psico-USF, 17(2), 195-203. http://dx.doi.org/10.1590/S1413-827120120002 00003

Garaigordobil, M. L. (1999). Assessment of cooperativecreative program of assertive behavior and selfconcept. The Spanish Journal of Psychology, 2(1), 3-10.

Garaigordobil, M. (2006). Intervention in creativity with children aged 10 and 11 years: Impact of a play program on verbal and graphic-figural creativity. Creativity Research Journal, 18(3), 329-345. http:// dx.doi.org/10.1207/s15326934crj1803_8

Guimarães, S. E. R. (2004). Motivação intrínseca, extrínseca e o uso de recompensas em sala de aula. In E. Boruchovitch \& J. A. Bzuneck (Eds.), Motivação do aluno: contribuições da psicologia contemporânea (pp.37-57). Petrópolis: Vozes.

Junge, L. A. R. (2006). Artes gráficas \& computação no processo educativo: um método para estimular o senso criativo (Dissertação de mestrado não-publicada). Universidade Regional de Blumenau.

Lin, Y. S. (2011). Fostering creativity through education: A conceptual framework of creative pedagogy. Creative Education, 2(3), 149-155. http://dx.doi.org/ 10.4236/ce.2011.23021

Ma, H. H. (2006). A synthetic of the effectiveness of single components and packages in creativity training programs. Creativity Research Journal, 18(4), 435-446. http://dx.doi.org/10.1207/s15326934crj1804_3

McCluskey, K. W. (2013). Thoughts about tone, educational leadership, and building creative climates in our schools. Ulm, Germany: ICIE.

Mendonça, P. V. C. F. (2012). Treinamento de criatividade com professores: efeitos na criatividade e no rendimento escolar de alunos com e sem transtorno de déficit de atenção e hiperatividade (Tese de doutorado não-publicada). Universidade de Brasília.

Nakano, T. C. (2009). Investigando a criatividade junto a professores: pesquisas brasileiras. Psicologia Escolar e Educacional, 13(1), 45-53. http://dx.doi.org/10.1590/ S1413-85572009000100006

Nakano, T. C. (2011). Programas de treinamento em criatividade: conhecendo as práticas e resultados. Psicologia Escolar e Educacional, 15(2), 311-322. http:// dx.doi.org/10.1590/S1413-85572011000200013

Nelson, L. J., Rubin, R. H., \& Fox, N. A. (2005). Social withdrawal, observed peer acceptance, and the development of self-perceptions in children ages 4 to 7 years. Early Childhood Research Quarterly, 20(2), 
185-200. http://dx.doi.org/10.1016/j.ecresq.2005. 04.007

Neves, E. R. C., \& Boruchovitch, E. (2007). Escala de Avaliação da Motivação para Aprender de alunos do ensino fundamental (EMA). Psicologia: Reflexão e Crítica, 20(3), 406-413. http://dx.doi.org/10.1590/s0 102-79722007000300008

Peixoto, J. B. (2003). Estudo das relações entre autoestima, autoconceito, rendimento acadêmico e dinâmicas relacionais com a família e com os pares em alunos do $7^{\circ}, 9^{\circ}$ e $11^{\circ}$ anos de escolaridade (Tese de doutorado não-publicada). Universidade do Minho, Braga, Portugal.

Pfeiffer, S. I., \& Wechsler, S. M. (2013). Youth leadership: A proposal for identifying and developing creativity and giftedness. Estudos de Psicologia (Campinas), 30(2), 219-229. http://dx.doi.org/10.1590/S0103-166 X2013000200008

Pinheiro-Cavalcanti, M. M. P. (2009). A relação entre motivação para aprender, percepção do clima de sala de aula para criatividade e desempenho escolar de alunos do $5^{\circ}$ ano do ensino fundamental (Dissertação de mestrado não-publicada). Universidade de Brasília.

Putwain, D. W., Kearsley, R., \& Symes, W. (2012). Do creativity self-beliefs predict literacy achievement and motivation? Learning and Individual Differences, 22(3), 370-374. http://dx.doi.org/10.1016/j.lindif.2011.1 2.001

Rojanapanich, P., \& Pimpa, N. (2011). Creative education, globalization and social imaginary. Creative Education, 2(4), 327-332. http://dx.doi.org/10.4263/ce.2011.24 046

Rose, L. H., \& Lin, H. (1984). A meta-analysis of longterm creativity training programs. The Journal of Creative Behavior, 18(1), 11-22. http://dx.doi.org/ 10.1002/j.2162-6057.1984.tb00985.x

Ryan, R. M., \& Deci, E. L. (2000). Intrinsic and extrinsic motivations: Classic definitions and new directions. Contemporary Educational Psychology, 25(1), 54-67. http://dx.doi.org/10.1006/ceps.1999.1020

Santos, F. C. G. (2014). Intervenção em criatividade com professoras e mães: efeitos no rendimento escolar, autoconceito, motivação e criatividade de alunos do $3^{\circ}$ ano do ensino fundamental (Tese de doutorado não-publicada). Universidade de Brasília.

Santos, F. C. G., \& Fleith, D. S. (2014). Criatividade em sala de aula e sua relação com autoconceito, rendimento escolar e motivação para aprender. AMAzônica: Revista de Psicopedagogia, Psicologia Escolar e Educação, 14(1), 46-70.

Sawyer, R. K. (2012). Explaining creativity. The science of human innovation ( $2^{\text {nd }}$ ed.). New York: Oxford University Press.

Scott, G., Leritz, L. E., \& Mumford, M. D. (2004). The effectiveness of creativity training: A quantitative review. Creativity Research Journal, 16(4), 361-388. http://dx.doi.org/10.1080/10400410409534549

Sisto, F. F., \& Martinelli, S. C. (2004). Escala de Autoconceito Infanto-Juvenil (EAC-IJ). São Paulo: Vetor.

Stadler, K., \& Kotze, M. E. (2006). The influence of a ropes course development programme on the selfconcept and self-efficacy of young career officers. Journal of Industrial Psychology, 32(1), 25-32. http:// dx.doi.org/10.4102/sajip.v32i1.225

Stein, M. (1974). Stimulating creativity: Individual procedures. New York: Academic Press.

Torrance, E. P. (1990). Torrance tests of creative thinking. Bensenville, IL: Scholastic Testing Service.

Virgolim, A. M. R., Fleith, D. S., \& Neves-Pereira, M. S. (2013). Toc, toc... plim, plim! Lidando com as emoções, brincando com o pensamento através da criatividade (12 ed.). Campinas: Papirus.

Wechsler, S. M. (1987). Efeitos do treinamento em criatividade em crianças bem-dotadas e regulares. Arquivos Brasileiros de Psicologia, 39(4), 95-110.

Wechsler, S. M. (2004a). Avaliação da criatividade por figuras ( $2^{a}$ ed.). Campinas: Impressão Digital do Brasil.

Wechsler, S. M. (2004b). Avaliação da criatividade por palavras ( $2^{a}$ ed.). Campinas: Impressão Digital do Brasil.

Wechsler, S. M., \& Souza, V. L. T. (Eds.). (2011). Criatividade e aprendizagem. São Paulo: Edições Loyola.

Recebido: fevereiro 11, 2015

Versão final: maio 11, 2015

Aprovado: maio 28, 2015 